\title{
Children's Global Assessment Scale
}

National Cancer Institute

\section{Source}

National Cancer Institute. Children's Global Assessment Scale. NCI Thesaurus. Code C155932.

A clinician-assessed rating of psychological and social functioning in children ages six to seventeen that was developed by Shaffer et al. in 1983. The numerical scale, which is an adaptation of the adult Global Assessment Scale (GAS) developed by Endicott et al in 1976, is scored from 0 to 100 based on behaviors and life situations that are applicable to children. 